\title{
The Valuation of Currency Put Options
}

\author{
Rebecca Abraham \\ Huizenga College of Business, Nova Southeastern University, Fort Lauderdale, USA \\ Email: abraham@nova.edu
}

How to cite this paper: Abraham, R. (2018) The Valuation of Currency Put Options. Theoretical Economics Letters, 8, 2569-2593. https://doi.org/10.4236/tel.2018.811165

Received: July 15, 2018

Accepted: August 21, 2018

Published: August 24, 2018

Copyright (C 2018 by author and Scientific Research Publishing Inc. This work is licensed under the Creative Commons Attribution International License (CC BY 4.0).

http://creativecommons.org/licenses/by/4.0/

\begin{abstract}
Investors who seek to profit from depreciating currencies may invest in put options. Upon option exercise, the currency is sold at a high price, and then purchased at the lower future currency value, resulting in a gain for the put buyer. A series of such transactions yields a stream of income for the put investor. Alternatively, the investor could short sell the currency, reaping gains from the difference between the high short sale price and the low future purchase price. This paper derives the theoretical formulations for combined short sale and puts purchase strategies for the US dollar, the Euro, the Australian dollar and the New Zealand dollar, and the Mexican peso. Utility functions are based upon an assumption of declining risk aversio with negative rescale factors and positive threshold factors in a hyperbolic cosine distribution. This distribution intersects with the cosine distribution of short sale prices on the U.S. dollar, the lognormal distribution of short sale prices on the Euro, the Weiner process for shorts on the Australian dollar and the New Zealand dollar, and the Laplace currency distribution for peso shorts. Similar utility functions intersect with Levy-Khintchine jump processes to provide put option prices for each type of foreign currency.
\end{abstract}

\section{Keywords}

Short Selling, Currency, Put Option, Lognormal, Weiner, Laplace

\section{Introduction}

Currency put options are only profitable with declining currency values. The Gain on a Currency Put $=($ Exercise Price - Spot Exchange Rate $)-$ Put Purchase Price. This outcome suggests that an investor, forecasting future currency depreciation, purchases a put option at the purchase price, sells the underlying currency at a high exercise price and buys back the currency at the lower future spot exchange rate, earning a gain. Conversely, an increase in currency values will result in a loss. If put buyers exercise, as Exercise Price $<$ Spot Exchange Rate, 
(Exercise Price - Spot Exchange Rate) - Put Purchase Price $<0$ ), therefore, the option will expire, with Loss $=(0-$ Put Purchase Price $)$.

There is a paucity of literature on currency put valuation and trading strategies. The existing literature explores currency call options which profit from increasing foreign currency prices. Watt [1], Daal [2], and Pitarbarg [3] developed call option currency valuation models, which did not account for the variation of foreign currencies with time. Schogl [4] included time distribution in a market-based model, while Mikkelson [5], Ahn [6] and Garman, etc. [7] introduced jumps into call valuation to account for discontinuities in the movement of foreign currencies with time. Therefore, the limitations in certain call models have been rectified in others. In contrast, limitations persist in the few currency put pricing attempts, such as 1) expressing put values as an extension of call prices, thereby omitting variables that are unique to put valuation, [8], 2) using the Black-Scholes model which underpriced out-of-the-money put options [9], 3) obtaining default risk, rather than put prices [10], and 4) assuming constant interest rates in a stochastic interest rate environment [11].

The purpose of this paper is to present a model of valuation of currency put options, based upon the premise that put options are a unique entity. Unlike currency calls, the market for currency puts has multiple participants. Short sellers attempt to gain from depreciating currencies. They borrow currencies, sell at high prices, and repay with cheap currency. Repeated short selling devalues currencies, raising concerns by regulatory authorities who view the devaluation as a loss of national wealth. Accordingly, they restrict short selling. This paper contributes to the literature in three ways. It is the first study to propose combined short selling and put buying strategies. An informed investor short sells currency in the foreign currency market, earns the modest gains, then ceases short selling upon restrictions imposed by regulatory authorities. Yet, he or she still has unsatiated demand for depreciating currencies, which may be fulfilled in the unregulated options market. Therefore, the trader purchases put options, devaluing currencies further. Secondly, the Miller model [12] envisions short sellers as rational investors, who sell overpriced currencies. The rationality of short sellers was borne out in empirical examinations in which short-sale restrictions prevented the sale of overpriced securities with high volume [13], and uncertain earnings forecasts by analysts and investors [14] [15] [16]. Our combined strategy of short selling with put buying provides insights into strategies of rationality linked with risk-taking in contrast to pure rationality or pure risk-taking. From a practitioner standpoint, this study assists investors in discovering the price level at which they should bid on currency put options. Thirdly, we present each joint short selling and put buying strategy in terms of its utility to the individual investor. Investors differ in their risk preferences, ranging from risk-averse to moderate risk-takers to gamblers. Therefore, we have three different model formulations for these different psychological value systems. We also distinguish among currencies. As the US dollar (world's reserve currency), the 
Euro (which fluctuates within a narrow band), the Australian and New Zealand currencies (liquid reserve currencies in high-interest rate economies), and the Mexican peso (volatile currency) are sufficiently different from each other, we create separate models for each one of them.

The remainder of this paper is organized as follows. Section 2 is a Review of Literature, Section 3 is a presentation of the joint short sale and put option formulations followed by valuation of put options, and Section 4 provides Conclusions.

\section{Review of Literature}

\subsection{An Overview of the Short Selling of Foreign Currencies}

A currency raid begins with signs of weakness in macroeconomic fundamentals. Speculators, often hedge funds, short sell the currency, being joined by other speculators, who aggressively drive the value of the currency to a minimum level. Morris [17] created a framework for analyzing the mechanism of currency raids and government intervention to protect currency values in order to maintain control of the money supply. The speculator's payoff is denoted by (Short Sale Currency Price - Purchase Price) - Short Sale Costs. As long as the currency depreciates significantly enough so that the Short Sale Currency Price - Purchase Price $>$ Short Sale Costs, the short seller will make a profit. If the government is successful in its intervention, Short Sale Costs $>$ (Short Sale Price Purchase Price), rendering the short sale strategy unprofitable. Short Sale Costs are typically the interest rates on the borrowed currency, which governments can set at a sufficiently high level to render short selling unprofitable. There may also be an intermediate phase in which short selling is partially profitable, wherein the interest rate is low enough so that a few rounds of short selling may take place before the gain from short selling is exceeded by the interest rate. The least profitable situation is when the currency appreciates, or when the Purchase Price $>$ Short Sale Price, as the short seller will need to repay the borrowed currency at a higher price than the original value. Central bank interventions to increase the interest rate on the currency, results in high interest differential portfolios termed carry trades which attract capital. Mettier, et al. [18] observed higher residual profit for carry trade strategies from 1998-2008 for daily and weekly time windows for 10 currencies. However, the high interest rates in economies that have weak macroeconomic fundamentals, such as weak aggregate consumption growth, are untenable, as Brunnermeir, et al. [19] found in an examination of 8 exchange rates, wherein the high interest rate differentials predicted depreciation of future exchange rates leading to currency collapses. These results were corroborated by Klitgaard, et al. [20] and Chen, et al. [21]) with the finding of the prediction by high interest rate differential portfolios of depreciating future exchange rates and elevated crash risk. Empirically, it has been found that only $26 \%$ - $38 \%$ of currency interventions by the US Federal Reserve from 1987-1990, to support European currencies have been successful [22]. 
A few special cases of central bank intervention may be noted. Political pressure from the United States to overcome the persistent depreciation of the US dollar has led to the Japanese central bank purchasing large quantities of US dollars, in a bid to support the value of the US dollar in the post-2010 period. Other central banks maintain their foreign reserves in US dollars due to the United States's economic size, developed financial markets, and historical practice [23]. Empirically, Shih, et al. [24] found that for 200 countries, from 2002-2008, political pressure from domestic institutions led to central bank accumulation of US dollar reserves. Support for the US dollar assures that any short sale profits are transitory in nature, with non-US central banks curbing short selling after a few rounds to maintain dollar values of their reserves. The European Monetary System, only permits a $0.5 \%$ fluctuation in the inflation rate, a $0.7 \%$ change in the long-term interest rate, and $0.25 \%$ change in government debt [25]. In the event of larger changes in these variables, or reduction in the Euro's value due to short-selling, the central bank will implement non-sterilized interventions. Non-sterilized interventions consist of the purchase of domestic currency or bonds with foreign currency, thereby increasing demand for the domestic currency, and in turn, the price of the domestic currency [26]. Alternatively, it has been suggested that the Euro be protected by the central bank borrowing the exact amount of international reserves as the domestic currency short sold by speculators. This reduces the currency to be borrowed by short sellers to zero, rendering it impossible for short sellers to complete their transactions [27]. With Australia or New Zealand, short selling may occur longer than the Euro, as market forces are less drastic in supporting declining currencies than central banks, permitting short selling for a longer period of time. In developing countries, the central bank may only be aware of short selling activity after currency values have depreciated significantly, so that non-sterilized interventions may not be successful in supporting currency values.

\subsection{Put Currency Options}

The first set of put currency option models are based on the [28] Call Option Pricing Model with Put-Call Parity for stocks, which was adapted by Garman, et al. [7] for currency options. The model may be stated as,

$$
C_{t}=S_{t} B_{t, T}^{*} N\left(d_{1}\right)+\sigma \sqrt{T-t}-X B_{t, T} N\left(d_{1}\right)
$$

where,

$$
d_{1}=\ln \left[S_{t} B_{t, T}^{*} / X B_{t, T}\right]-1 / 2 \sigma^{2}(T-t) \sigma \sqrt{(T-t)}
$$

Put-Call Parity yields the value of a put option,

$$
P_{t}=X B_{t, T} N\left(-d_{1}\right)-S_{t} B_{t, T}^{*} N\left(-d_{1}\right) / \sigma \sqrt{(T-t)}
$$

$C_{t}=$ Value of Call Option in Foreign Currency at time $t, S_{t}=$ Spot Echange Rate at time $t,(T-t)=$ Time to maturity, $B_{t, T}^{*}=$ Price of a Foreign Currency Bond at time $t, N\left(d_{1}\right)=$ Cumulative Normal Density Function, $\sigma=$ Volatility of 
the Spot Currency Price, $X=$ Exercise Price of the Call Option, $B_{t, T}=$ Price of a Domestic Currency Bond at time $t, P_{t}=$ Value of Put Option in Foreign Currency at time $t$.

This formulation assumes that the investor owns a domestic bond and a call option and sells a foreign bond and a put option. The only differences from the Black-Scholes model are that 1) the stock price is replaced with the spot exchange rate, as the underlying asset is foreign currency, not stock, 2) domestic and foreign bonds are included, and, 3) time to maturity is computed as $(T-t)$, instead of $t$. Similarities outweigh differences, including, 1) the assumption of a geometric Brownian motion for the movement of currency prices over time. However, currencies have values set by government policy, which have been shown to depart from a geometric Brownian motion [29]. 2) stock return distributions do not account for the jumps in currency option distributions, 3) volatility is assumed to be deterministic in the Black-Scholes model, as the formation of a riskless hedge, whereby stocks are purchased and options are sold, permits any increase in volatility from the stock to be neutralized by the option, and vice versa. An options-only strategy would not be able to mitigate the high volatility of put options, indicating that skewness and kurtosis must be considered separately for currency options. The remainder of the papers reviewed in this section attempt to resolve some of these limitations, with varying degrees of success.

The [30] model merely replaces the returns on the bonds in (1) with domestic and foreign interest rates, and the spot exchange rate with the forward rate, so that their put formula is,

$$
P=C+(X-F) \mathrm{e}^{-r t} \text {, where } F=\text { forward rate }
$$

This substitution may be an improvement over the Black-Scholes-based formulation in that the forward rate approximates the return on a put option more closely than bond returns. Returns on riskless bonds are typically lower than those on risky puts. The forward rate, on the other hand, is based on market-based judgements of future exchange rates, and may therefore, be more realistic in predicting returns on put options than risk-free bonds. However, both the [30] and [7] models did not provide accurate volatility measures underpricing put and call prices for four currencies from 1982-1984 [9] [31].

The above models omit the inclusion of jumps in currency options. A series of studies [32] [33] [34] introduced jumps into option pricing, given that currency options have been observed to have jump discontinuities in a discrete Poisson process. The movement of put option prices is discontinuous. They exhibit breaks with sharp changes in prices with currency values either increasing (positive skewness) or decreasing (negative skewness) in the future. Consequently, other distributions than a normal distribution with jumps, have been considered to model put option prices. The fractional Brownian motion introduced jumps [35], but still bears striking similarity to the [30] model in that it is another form of the same Brownian motion used in earlier formulations. A completely different distribution is the Levy jump process [36]. It dispenses with the assumption 
of normality altogether, as well as the need to form a riskless hedge, by combining a stock with options. Also, the final option price is based on the Laplace transform of a nonlinear, non-normal distribution that describes the path of a put option in an options-only model. This formulation overcomes each of the limitations of the Black Scholes-based models listed above.

\subsection{Investor Preferences}

Both short selling and put buying strategies are risky. Profits are only earned if currency prices depreciate, with greater payoffs as currency depreciation continues and reaches a minimum level. Not all traders wish to maximize profits. Risk-averse investors will be satisfied with minimal profits, exiting both short selling and put buying if they suspect that short sale borrowing rates will eliminate profits, or that put premiums will rise to overwhelm put gain. Other investors may trade in a few rounds of short selling or put buying, achieving satiation of payoffs with higher short sale or put buy gains. Risk-takers will pursue maximum gain, trading to the last round of either strategy. In other words, the attitude to risk of each type of trader governs the investment choices made and the prices they are willing to pay. One type of attitude is absolute risk aversion. Absolute risk aversion is the innate attitude to risk based on values, beliefs and personal predispositions. Such attitudes are only likely to change under exceptional circumstances. For example, both Pratt [37] and Prakash, etc et al. [38] derived utility functions in which managers, who were offered windfall profits in an unexpected opportunity, accepted them in utility functions with decreasing absolute risk aversion.

Certain utility functions of investor preferences omit changes in risk aversion altogether. In both [39] and [40] the utility function $=$ (Wealth - Consumption), with increases in wealth being governed by an increase in the price of the option over time. Brennan [39] made an allowance for the probability of assessment of outcomes to vary. For example, one investor may consider option profits to continue for two rounds. Another investor may consider option profits to continue for three rounds. Yet, whether they capitalize on these outcomes depends on their absolute and relative risk aversions, or their attitudes to risk. Therefore, this study models investor preferences based on risk aversions. Both of these papers indicate that the utility function of the investor and that of the option have identical distributions (lognormal for [39], and hyperbolic cosine lognormal for [40]), since utility is only governed by price of the foreign currency. As this paper views utility as being determined by personal beliefs or demographic factors, price is not the only variable that explains utility of consumption.

Pratt [36] quantified the change in absolute risk aversion as the payment that permits a trader to accept a risky put option investment where the payment is a function of the projected mean of the deviation from current payoffs, $E(z)$, together with $\sigma$, the variance of the deviation from its projected path. This change in absolute risk aversion may otherwise be considered as the third derivative of 
the deviation from current payoffs. Prakash, et al. [37] took the concept of changing absolute risk aversion to a condition for acceptance of the ultra-risky gamble, say, of investing in put options near the minimum currency price as,

$$
-\left[p \theta(\theta-2 \Pi b)+\Pi^{2} b\right] m_{1} / 2<\left[p \theta\left(\theta^{2}-3 \theta \Pi b+3 \theta \Pi^{2} b\right)-\Pi^{3} b\right] m_{2} / 6
$$

Or, (Small gain $\times$ absolute risk aversion) $<$ (Large gain $\times$ change in absolute risk aversion). Therefore, for a risk-averse individual, only a substantial increase in gain would permit acceptance of the riskiest put or short sale choices.

\section{Pricing Put Options}

\subsection{Pricing Put Options on the U.S. Dollar}

Three types of investor utility functions will be considered with investors first embarking on short selling. Then, they may or may not engage in put buying. The put strategy will lead to a put distribution, which when weighted by put prices will yield the final expression for the put value.

Case 1: The Risk-Averse Investor. The risk-averse investor has a coefficient of absolute risk aversion, $m_{1}>0$, or will only accept an investment if certain that the payoff will not result in loss, which could occur if short sale prices or put prices trend upwards. Therefore, this strategy may be confined to 2 rounds of short selling, before foreign governments realize that they need to support the US dollar, and start purchasing it for their reserves. The investor's utility function may be modeled by an hyperbolic cosine distribution, shown in Figure 1, as this distribution has non-negativity, a symmetrical declining slope function $N R$, indicating decreasing risk aversion over time along with a negative scale parameter $Q$, and a positive threshold parameter $N$, intersecting the vertical axis. The investor borrows to purchase the U.S. dollar at the highest price, waits for the dollar to depreciate in two rounds of trading, and then completes the transaction by repaying with cheaper dollars. The movement of U.S. dollar values during the 2 rounds is depicted in curve $O S P$, which is described by a cosine function. The cosine function is in the form of a wave, with short sale prices alternately increasing and decreasing. Investor preferences and short sale prices intersect at $S$, at which the investor takes the gain from short selling $[(P-\Pi)] \times$ Units $-t r]$, where $P=$ sales price per unit, $\Pi=$ cost per unit, and $t r=$ interest costs, and exits the market.

$$
\begin{aligned}
F= & \sum x^{2 n} /(2 n) !+\int a+(€) \cos (2 \Pi €(x+t)) \\
& +a-(€) \cos (2 \Pi €(x-t))+b+(€) \sin (2 \Pi €(x+t)) \\
& +b-(€) \sin (2 \Pi €(x-t)) d €+d / d x\left[(x-\mu)^{3} / \sigma\right]
\end{aligned}
$$

First term $=$ Taylor series expansion of a hyperbolic cosine distribution, Remaining terms $=$ Cosine distribution of short sale prices, and Skewness of short sale prices.

Taking derivatives of Equation (6) to explain the change in risk aversion and change in short sale prices to point $S$. 


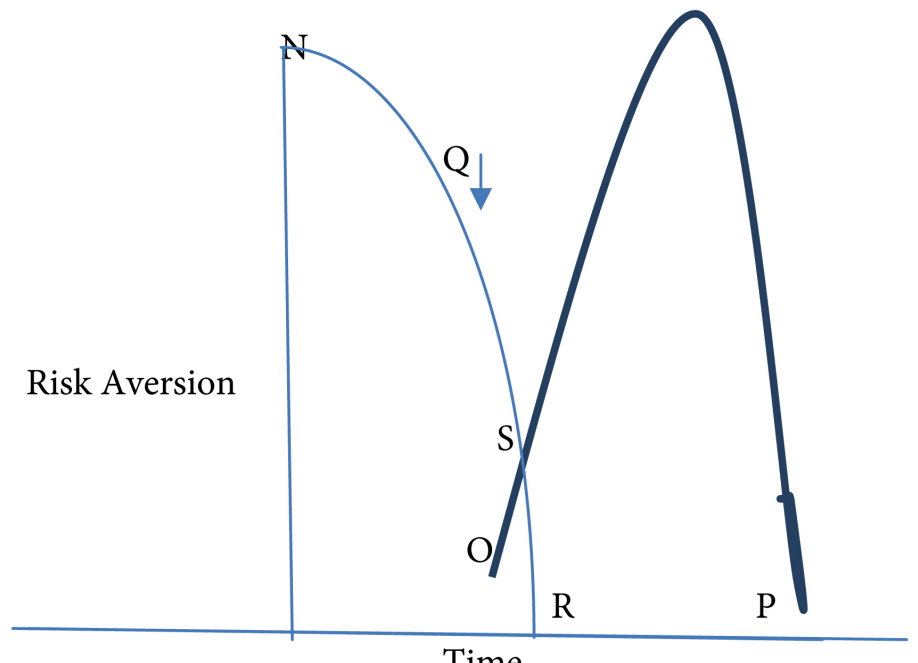

Time

Figure 1. Short sale transactions for risk-averse investors in U.S. Dollars. Short sellers become more willing to accept risk, with decreasing risk aversion along curve $N R$, which intersects the cosine price function, $O P$, at $S$, the optimal price. Source: Section 3.1, This Paper.

For the hyperbolic cosine distribution, the derivative is given by inserting Ito's multiplication rule into the Taylor series in Equation (6). For the cosine series, the derivative is given by applying Euler's formula. For the skewness, we find the derivative of a Laplace transform,

$$
\begin{aligned}
& {\left[(d G / d x) a+(d G / d t)+0.5\left(d^{2} / d x^{2}\right) b b\right] d t+(d G / d x) b d z} \\
& +\left[\left(e^{-i a x}+e^{-i a x}\right)\right] / 2+s * L\left\{(x-\mu)^{3} / \sigma\right\}
\end{aligned}
$$

The necessary condition for the investor to achieve maximum gain is described by the following linear programming model.

Maximize

$$
\begin{aligned}
& (S-P) *\left[(d G / d x) a+(d G / d t)+0.5\left(d^{2} / d x^{2}\right) b b\right] d t+(d G / d x) b d z \\
& -\theta\left[\left(e^{i a x}+e^{i a x}\right)\right] / 2-s * L\left\{(x-\mu)^{3} / \sigma\right\}
\end{aligned}
$$

where $(S-P)$ is the gain on the short sale transaction and $\theta$ is the Lagrange multiplier that relates the cosine distribution of short sale prices and their skewness to the satisfaction of the need by the risk-averse consumer for depreciating currency.

The sufficient condition for the achievement of maximum gain is the second derivative of Equation (8) equated to 0 ,

$$
\begin{aligned}
& (S-P) *\left[\left(d^{2} G / d x^{2}\right) a+(d G / d t)+\left(d^{2} / d x^{2}\right) b^{2}\right] d t+d^{2} G / d x^{2} b d z \\
& +\theta\left[\left(e^{i a x}+e^{i a x}\right)\right] / 2+s * L^{\prime}\left\{(x-\mu)^{3} / \sigma\right\}=0
\end{aligned}
$$

Since the third derivative is an aberration [37], which does not apply to the risk-averse investor, we may reduce the third derivative in Equation (9) to 0, 


$$
\begin{aligned}
& (S-P) *\left[\left(d^{2} G / d x^{2}\right) a+d G / d t+d^{2} G / d x^{2} b d z\right. \\
& \left.+\theta\left[\left(e^{i a x}+e^{i a x}\right)\right] / 2+s * L^{\prime}\left\{(x-\mu)^{3} / \sigma\right\}\right]=0
\end{aligned}
$$

\section{Case 2: The Moderate Risk-Taker}

The moderate risk taker may see more potential for profit in short selling, engaging in three rounds of short selling, after which central bank intervention renders short selling unprofitable. The liquidity of the US Dollar permits more short selling than other currencies, as a large volume of dollars is available to trade. Consequently, we introduce a lower price bound to short selling, after which the risk-taker continues trading in the options market, purchasing puts for about two rounds of trading, before currency prices rise and put profits are exhausted. The investor exercises the put at points $P$ and $R$, at which his or her utility function of risk preferences, $A B$, intersects with the put Levy-Khintchine distribution, $O S$ (see Abraham, in press, for a review of Levy-Khintchine jump processes). Therefore, Figure 1 applies to short selling transactions, while Figure 2 depicts utility function interactions with put option purchases.

Taking derivatives of Equation (6) will explain the change in risk aversion and change in short sale prices to point $S$, For the hyperbolic cosine distribution, the derivative is given by inserting Ito's multiplication rule into the Taylor series in Equation (6), for the cosine series, it is applying Euler's formula, and for the skewness, it is finding the derivative of a Laplace transform. A Laplace transform is employed to suppress the considerable skewness of the heavily traded US dollar, which fluctuates with positive and negative skewness.

$$
\begin{aligned}
& {\left[(d G / d x) a+0.5\left(d^{2} G / d x^{2}\right) b b d t+d G / d x b d z\right.} \\
& \left.+\left[\left(e^{-i a x}+e^{-i a x}\right)\right] / 2+s * L\left\{(x-\mu)^{3} / \sigma\right\}\right]
\end{aligned}
$$

when the investor is satisfied with the gain from short selling, he or she imposes a lower price bound to the cosine short sale distribution (see Equation (12) and Equation (13)).

The Fourier sine and cosine forms of a boundary condition are,

$$
2 y(x, 0) \cos \int(2 \Pi € x) d x=a+a-
$$

and

$$
2 \int \partial y(u, 0) / \partial t \cos (2 \Pi € x) d x=2 \Pi €(b+b-)
$$

Substituting $t=0$ in the wave equation that satisfies the Fourier transform,

$$
\begin{gathered}
y(x, t)=\int a+€ \cos (2 \Pi €(x+t))+a-€ \cos (2 \Pi €(x-t)) \\
+b+€ \sin s(2 \Pi €(x+t))+b \cdot €(x-t) d € \\
y(x, 0)=\int a+€ \cos (2 \Pi € x)+a-€ \cos (2 \Pi € x) \\
+b+€ \sin (2 \Pi € x)+b-\sin € x, d €
\end{gathered}
$$

Multiply (15) by $\cos (2 \Pi € x)$, and assume all $x>0$, 


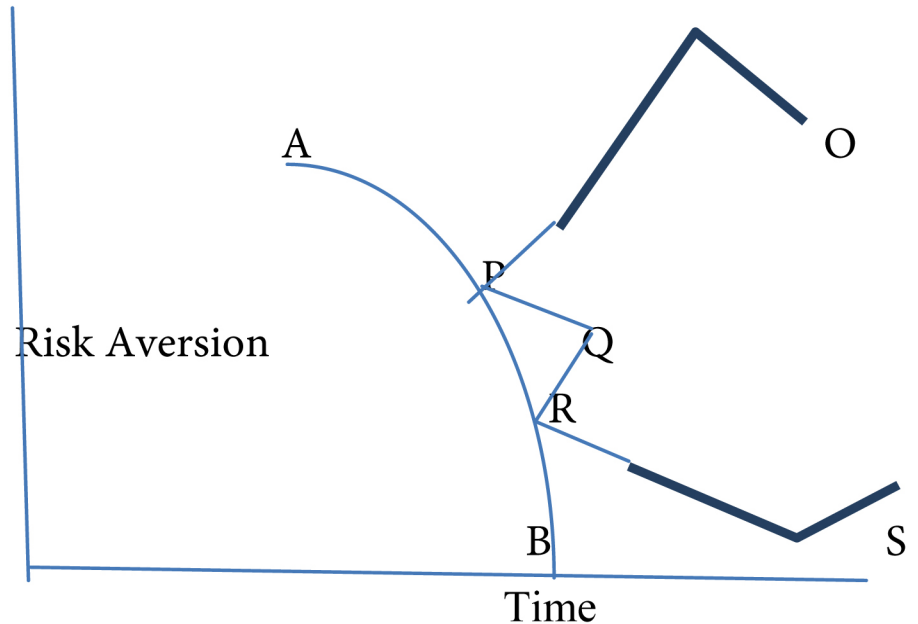

Figure 2. Put buy transactions for moderate risk takers in the U. S Dollar. Put buyers' hyperbolic cosine distributed utility functions at $P$ and $R$, at which U.S. dollars are sold, and repurchased at $O$ and $S$. Source: Section 3.1, This Paper.

$$
\begin{aligned}
a+a-= & a+€ \cos ^{2}(2 \Pi € x)+a-€ \cos ^{2}(2 \Pi € x)+b+\cos (2 \Pi € x) \\
& € \sin (2 \Pi € x)+b-\cos (2 \Pi € x) € \sin x, d €
\end{aligned}
$$

By the same token,

$$
\begin{aligned}
b+b-= & a+€ \cos (2 \Pi € x)+a-€ \cos (2 \Pi € x) \\
& +b+€ \sin ^{2}(2 \Pi € x)+b-€ \sin 2 x d €
\end{aligned}
$$

Solving (16) and (17) will yield the boundary for short selling.

At points $P$ and $R$ in Figure 2, investor preferences intersect with the Levy-Khintchine distribution of jumps in U.S. dollar values to yield the highest gain. The Levy-Khintchine distribution is obtained as in Abraham (in press). The first jump in Figure 1 will be represented by

$$
\int\left(e^{i} \theta x t-1-i \theta x t I\left|x_{t}<1\right|\right) \Pi(d x)
$$

The lowest point of this jump, at which the investor will realize the maximum gain from investing in the put option is the second derivative of Equation (18). Differentiating the investor's utility hyperbolic cosine distributed utility function below,

$$
=2 n(x) / 2 n !
$$

At maximum gain, the second derivative of the utility function in Equation $(19)=0$. Equating (19) and (20) and including the Laplace transform adjustment for skewness from Equation (12),

$$
=-e^{i} \theta x t+i \theta x t I|x<1| \Pi(d x)+s * L\left\{(x-\mu)^{3} / \sigma\right\}=0
$$

Equation (20) provides a solution for $x$, the optimal point of the intersection of the utility function and the Levy-Khintchine process. The put price is given by, 


$$
\begin{aligned}
P= & (X-S-p p) * 1 / 2 n x / 2 n !\left(-e^{i} \theta x t+i \theta x t I|x t<1|\right) \Pi(d x) \\
& +s * L\left\{(x-\mu)^{3} / \sigma\right\}
\end{aligned}
$$

\section{Case 3: The Risk-Taker}

The trader engages in short selling, until a lower limit on short selling is reached. Therefore, the expressions contained in Equation (11), Equation (12), Equation (13), Equation (14), Equation (15), Equation (16), Equation (17), Equation (18), and Equation (19) will be used in this section. Upon reaching the boundary of short selling, the trader moves to the options market to purchase puts. Being a risk-taker, the trader may wish to continue purchasing put options until the minimum U.S. dollar value is reached. Yet, given the heightened risk, he or she may insist on being paid a premium for taking the risky gamble. We add the [38] risk aversion adjustment to the hyperbolic cosine utility function in Equation (22),

$$
\begin{aligned}
& (X-S) *\left[(d G / d x) a+d G / d t+0.5\left(d^{2} x / d x^{2}\right) b b\right] d t+(d G / d x) b d z \\
& {\left[X S(X-2 S)+S^{2}\right] m_{1} / 2-\left[X S\left(X^{2}-3 X S+3 S^{2}\right)-S^{3}\right] m_{2} / 6 .}
\end{aligned}
$$

where First 4 terms = Ito's lemma of the hyperbolic cosine distribution, $X-S=$ Exercise Price of the Put Option - Spot Exchange Rate Last 3 terms = Function for the acceptance of an unlucky gamble, $m_{1}=$ coefficient of absolute risk aversion, $m_{2}=$ change in the coefficient of absolute risk aversion. This utility function in Equation (22) is equated to the premium, $Y$, that must be paid to the trader for assuming additional risk, The above utility function in Equation (22) intersects the Levy-Khintchine formula for the put distribution, so the maximum gain from the put option investment is achieved at the intersection of the utility function and the second derivative of the Levy-Khintchine process.

$$
\begin{aligned}
& (X-S) *\left[(d G / d x)+d G / d t+0.5\left(d^{2} / d x^{2}\right) b b\right] d t+d G / d x b d z \\
& -\frac{\left[X S(X-2 S)+S^{2}\right] m_{1}}{2}-\left[X S\left(X^{2}-3 X S+3 S^{2}\right)-S^{3}\right] m_{2} / 6 \\
& -Y=0=\left(-e^{i} \theta t+i \theta x I|x<1|\right) \Pi+s^{*} L^{\prime}\left[(x-\mu)^{3} / \sigma\right]
\end{aligned}
$$

Solving for $X$,

$$
\begin{aligned}
x= & (X-S) *\left[(d G / d x) a+d G / d t+0.5\left(d^{2} / d x^{2}\right) b b\right] d t+d G / d x b d z \\
& -\left[X S(X-2 S)+S^{2}\right] m_{1} / 2-\left[X S\left(X^{2}-3 X S+3 S^{2}\right)-S^{3}\right] m_{2} / 6 \\
& -Y /\left(-e^{i} \theta x+i \theta I|x|<1\right) \Pi+s^{\prime} * L^{\prime}\left[(x-\mu)^{3} / \sigma\right]
\end{aligned}
$$

\subsection{Pricing Put Options on the Euro}

\section{Case 1: The Risk-Averse Investor.}

The macroeconomic parameters to qualify for the European Union's exchange rate target of $0 \%-1 \%$ of normal rates is $0 \%-0.5 \%$ fluctuation in the inflation rate, $0 \%-0.7 \%$ change in the long-term interest rate, and $0 \%-0.25 \%$ change in 
government debt [25].

Figure 3 depicts the short sale transactions undertaken by the risk-averse investor. The investor is aware of the fact that the Euro may only fluctuate within a narrow band, whose lower limit is $A B$. The Euro's movements are presented along $U V$. Therefore, only a limited amount of short selling is possible, as any decline in the Euro is offset by immediate central bank intervention to preserve the target rate. Figure 3 shows that the hyperbolic cosine utility function, $O S$, slopes downwards with decreasing risk aversion. At point $T$, the maximum short sale gain at the minimum short sale price is realized, with the intersection of the hyperbolic cosine utility function with the lognormally distributed function of short sale prices, $U V$. A lognormal distribution is employed as it takes the form of a gradual descent in prices, as opposed to the steeper slope of the cosine distribution, and the monotonically negative values of the sine or tangent distributions. Equation (25) shows point $T$, the point of intersection of the hyperbolic cosine distribution and the lognormal distribution,

$$
\begin{aligned}
\sum x^{2 n} /(2 n) ! & =\left[(x-\mu) Z^{3} / \sigma\right]+e^{\mu}+1 / 2 \sigma^{2} \phi\left(\mu+\sigma^{2}-\ln k_{1}\right) / \sigma+e^{\mu} \\
& =1 / 2 \sigma^{2} \phi\left(\mu+\sigma^{2}-\ln k_{2}\right) / \sigma+e^{\mu}+1 / 2 \sigma^{2} \phi\left(\mu+\sigma^{2}-\ln k_{3}\right) / \sigma
\end{aligned}
$$

where, First term $=$ Taylor series expansion of a hyperbolic cosine distribution, $e^{\mu}$ $=1 / 2 \sigma^{2}$ quantities $=$ partial expectation of a short sale price, $x$, conditional upon the spot rate, $x<k_{1}$, or $k_{2}$, or $k_{3}$, where $k_{1}$ is the targeted inflation rate, $k_{2}$ is the targeted long-term interest rate, and $k_{3}$ is the targeted amount of government debt, A necessary condition for maximum short sale gain is the first derivative of Equation (23),

$$
\begin{aligned}
& \sum 2 n x /(2 n) !-3\left[(x-\mu)^{2} / \sigma\right]-e^{\mu}+1 / 2 \sigma^{2} \mathrm{~d} / \mathrm{d} x \phi\left(\mu+\sigma^{2}-\ln k_{1}\right) / \sigma-e^{\mu} \\
& =1 / 2 \sigma^{2} \phi\left(\mu+\sigma^{2}-\ln k_{2}\right) / \sigma-e^{\mu}+1 / 2 \sigma^{2} \phi\left(\mu+\sigma^{2}-\ln k_{3}\right) / \sigma,
\end{aligned}
$$

Using Ito's Lemma, where $G 1=\left(x+\mu^{2}-\ln k_{1}\right) / \sigma, G 2=\left(x+\mu^{2}-\ln k_{2}\right) / \sigma$, $G 3=\left(x+\mu^{2}-\ln k_{3}\right) / \sigma$,

$$
\begin{aligned}
& \sum / 2 n !-3\left[(x-\mu)^{2} / \sigma\right]-e^{\mu}+1 / 2 \sigma^{2}\left[\partial G_{1} / \partial x d x+\partial G_{1} / \partial t+1 / 2 \partial^{2} G_{1} / \partial x^{2} b^{2} d t\right. \\
& \left.+\partial G^{2} / \partial x d x+\partial G^{2} / d t+1 / 2 \partial G^{2} / \partial x^{2} b^{2} d t+\partial G_{3} / \partial t+1 / 2 \partial^{2} G_{3} / \partial x^{2} b^{2} d t\right]
\end{aligned}
$$

Differentiating Equation (25) yields the sufficient condition for short sale gain,

$$
\begin{aligned}
& \sum 2 n x /(2 n) !-6[(x-\mu) / \sigma]+e^{\mu}+1 / 2 \sigma^{2}\left[\partial^{2} G_{1} / \partial x^{2} d x+\partial G_{1} / \partial t\right. \\
& +1 / 2 \partial^{2} G_{1} / \partial x^{3} b^{2} d t+\partial^{2} G_{2} / \partial^{2} x d x+\partial G_{2} / \partial t+1 / 2 \partial^{3} G_{2} / \partial x^{3} b^{2} d t \\
& \left.+\partial^{2} G_{3} / \partial x^{2} d x+\partial G_{3} / \partial t+1 / 2 \partial^{3} G_{3} / \partial x^{3} b^{2} d t\right]
\end{aligned}
$$

After a few rounds of short selling, the risk averse investor is confronted with the sudden appreciation of the Euro, as the central bank forces the Euro into the narrow band. Then, the investor continues trading put options. As shown in Figure 4, the investor exercises the put option at the peak of the option price 


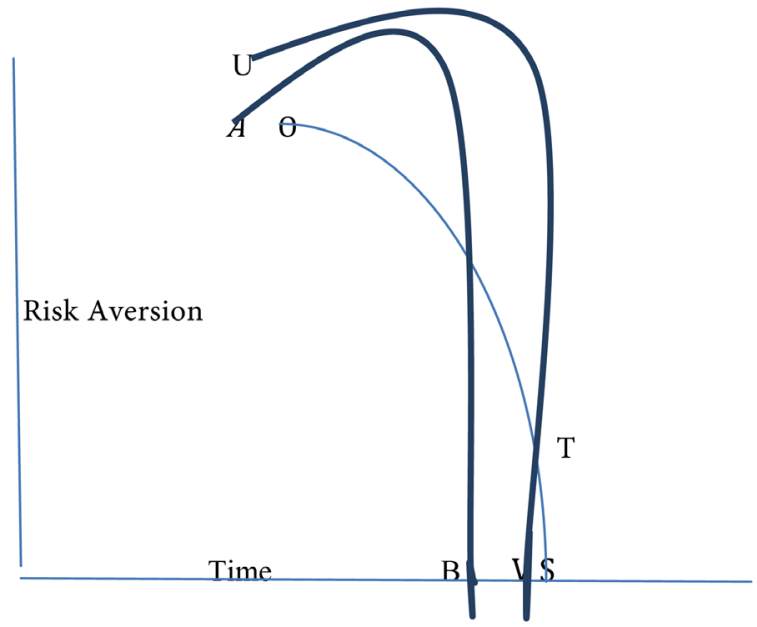

Figure 3. Short sale transactions by risk-averse Euro Investors. Minimal gain to investors from short selling at $T$, the intersection of the $O S$ utility function and the $U V$ price function. Source: Section 3.2 This Paper.

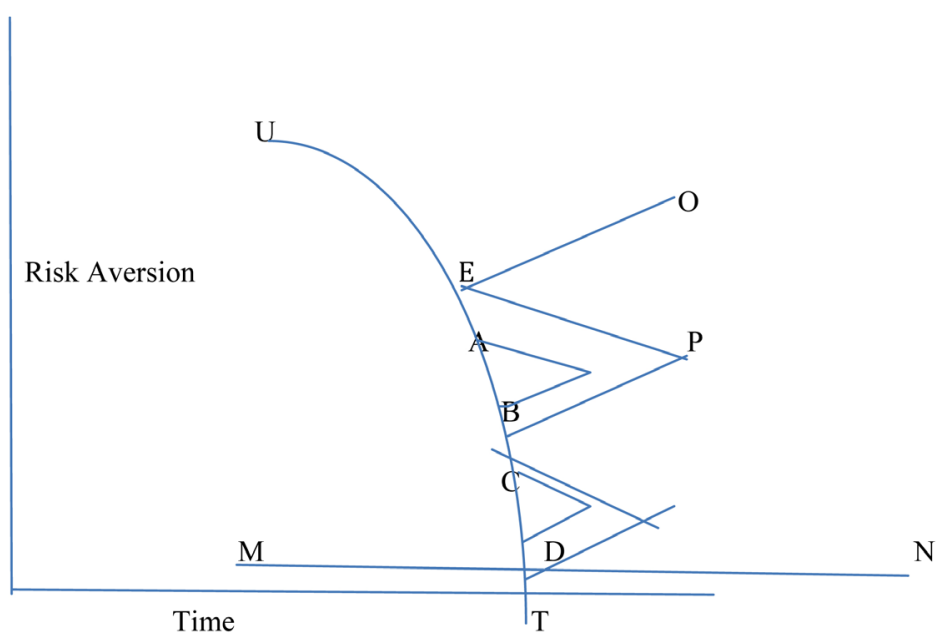

Figure 4. Put buy transactions for risk-averse Euro Investors. The put buyers' utility function, $U T$, intersects with $O D$, the put option price function at $E, A, B, C$, and $D$, where selling of euros occurs with repurchases for gain upon price decrease. Source: Section 3.2, This Paper.

jump, selling the Euro at the exercise price, $X$, and repurchasing it at the spot rate at point, $P$, thus realizing a gain. The Euro band, $A B$, imposes a lower limit below which the Euro may not decline. The investor's utility function intersects with the Levy-Khintchine distribution of put prices at $X$.

The price of a put option

$$
\begin{aligned}
= & (X-S-p p) * \sum 2 n x /(2 n) !-6[(x-\mu) / \sigma]+e^{\mu}+1 / 2 \sigma^{2}\left[\partial^{2} G_{1} / \partial x^{2} d x\right. \\
& \left.+\partial^{2} G_{1} / \partial t^{2}+1 / 2 \partial^{3} G_{1} / \partial x^{3} b^{2} d t+\partial^{2} G_{3} / \partial x^{2} d x+\partial^{2} G_{3} / \partial t\right]
\end{aligned}
$$

where, $X=$ Exercise price, $S=$ Spot rate, $P p=$ Put premium, At the maximum point of the gain, the second derivative the utility function is equated to the Levy-Khintchine distribution, 
The spot rate for maximum put gain for the risk-averse investor

$$
=2 n\left[\left(e^{i} \theta x-i \theta x I|x<1|\right) \Pi+s^{*} L^{\prime}\left\{(x-\mu)^{3} / \sigma\right\}\right] /[2 n !]=x
$$

It follows that the put price,

$$
P=(X-S-p p) *\left(e^{i} \theta x-i \theta x I|x<1|\right) \Pi 2 n ! / 2 n
$$

$X=$ Exercise price of the put option, $S=$ Spot exchange rate of the Euro, $p p=$ Put premium, $s \times L$ 'term $=$ Laplace transform adjustment for skewness.

\section{Case 2: The Moderate Risk-Taker}

Using Prakash, et al. [38]'s transformation, the investor becomes less risk-averse, upon perceiving the probability of future gain leading to the acceptance of risky short selling,

$$
m_{2} / 3 m_{1}=1 /(\theta-1)
$$

where, $m_{2}=$ elasticity of absolute risk aversion, $m_{1}=$ coefficient of absolute risk aversion, Right side of Equation (32) = loss from short selling, These risk-takers know that gains may be earned during the narrow window of time during which the Euro declines below the band $A B$ in Figure 5, and the central bank intervention. The current loss is acceptable, if a future payoff (found in the right side of Equation (33)) is forthcoming,

$$
1 /(\theta-1)<(\theta-2) /\left(\theta^{2}-3 \theta+3\right)
$$

Over time, acceptance of risky short selling grows. In Figure 5, the coefficient of absolute risk aversion tends to the point $T$, along the curve, PS. At the point $T$ in Figure 5, the investor's utility function intersects with the lognormal distribution of short sale prices. Equating these two expressions and taking the first derivative of both sides to meet the necessary condition to maximize utility,

$$
\begin{aligned}
& (X-S) *\left[(\mathrm{~d} G / \mathrm{d} x) a+\mathrm{d} G / \mathrm{d} x+1 / 2\left(\mathrm{~d}^{2} x / \mathrm{d} x^{2}\right) b^{2} \mathrm{~d} t+\mathrm{d} G / \mathrm{d} x b \mathrm{~d} z+\left(m_{2}-1\right) / 3 m_{1}\right] \\
& =\left[e^{\mu}+\sigma^{2} \phi\left(\mu+\sigma^{2}-\ln k_{1}\right) x / \sigma\right]+\left[e^{\mu}+\sigma^{2} \phi\left(\mu+\sigma^{2}-\ln k_{2}\right) x / \sigma\right] \\
& +\left[e^{\mu}+\sigma^{2} \phi\left(\mu+\sigma^{2}-\ln k_{3}\right) x / \sigma\right]+\left(e^{\sigma 2}+2\right) \sqrt{\left(e^{\sigma 2}-1\right)} \\
& +\left(x^{4} \sigma^{2}+2 x^{3} \sigma^{2}+3 x^{2} \sigma^{2}-6\right)
\end{aligned}
$$

Last 2 terms in Equation (34) = Measures of skewness and kurtosis, to satisfy the sufficient condition to maximize utility, differentiate Equation (34),

$$
\begin{aligned}
(X-S) & \left.\left(\mathrm{d}^{2} G / \mathrm{d} x^{2}\right)+\mathrm{d} G / \mathrm{d} t+1 / 2\left(\mathrm{~d}^{3} x / \mathrm{d} x^{2}\right) b b d t+d^{2} G / d x^{2} b d z+\left(m_{2}-1\right) / 3 m_{1}\right] \\
= & e^{\mu}+\sigma^{2} \phi\left(\mu+\sigma^{2}-\ln k_{1}\right) / \sigma+e^{\mu}+\sigma^{2} \phi\left(\mu+\sigma^{2}-\ln k_{2}\right) / \sigma \\
& (e \sigma 2+2) 1 / 2(e \sigma 2-1)-1 / 2+4 \sigma 2 \times 3 \sigma 2+6 \times 2 \sigma 2+6 x \sigma 2
\end{aligned}
$$

In Figure 6, the investor purchases puts, with maximum gain at point $T$, where the utility function intersects the peak of the jump. $A B C D$ represents the lower limit of Euro values. At the peak, the Euro is sold, and then purchased at the lower trough price. Equating Equation (35) with the first derivative of the Levy-Khintchine put distribution with adjustments for skewness and kurtosis to 


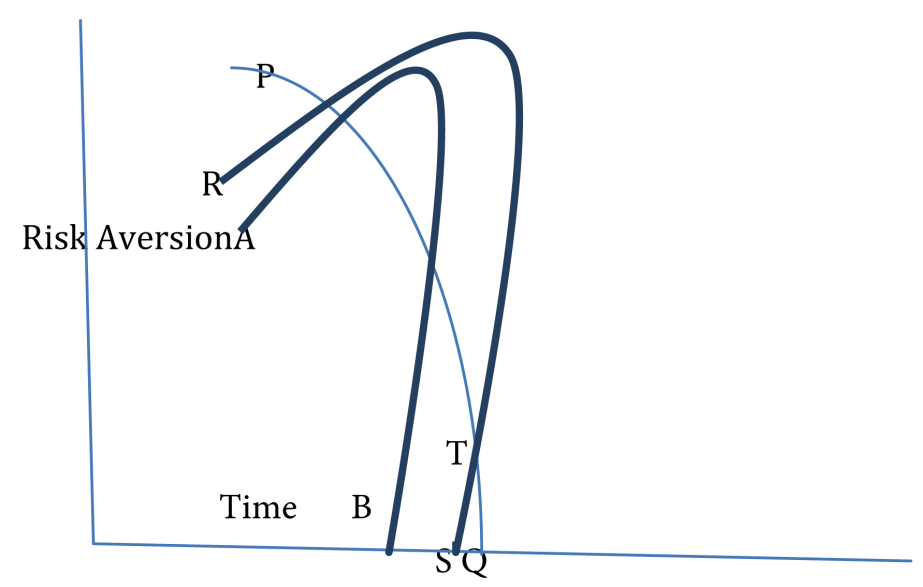

Figure 5. Short-sale transactions of the moderate risk-taker. Short sales occur at $T$, the intersection of the investor's utility function, $P Q$, and the lognormal distribution of Euro prices, to deliver gains upon repayment of lower-priced Euros. Source: Section 3.2, This Paper.

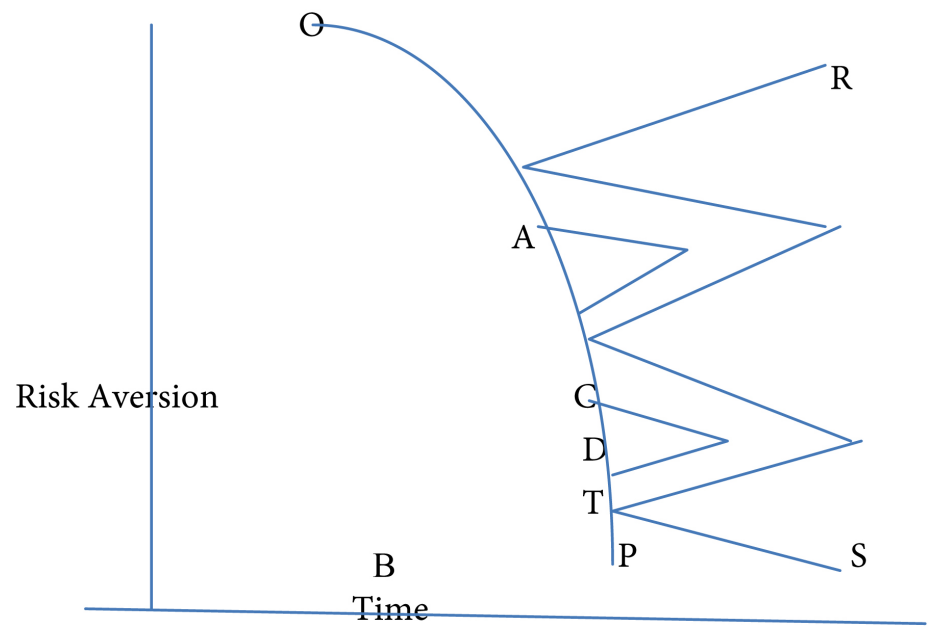

Figure 6. Put purchase transactions of the Euro by moderate risk-takers. Put buyers exercise at $T$, the point of intersection of the utility function, $O P$, with the price distribution within the Euro band. Repurchase for gain occurs at the trough of the Levy-Khintchine distribution of option prices. Source: Section 3.2, This Paper.

yield the necessary condition,

$$
=e^{i} i \theta x+i \theta x I|x|, 1 \Pi+s L^{\prime}\left\{(x-\mu)^{3} / \sigma\right\}
$$

The sufficient condition for the maximization of put gain is obtained by differentiating Equation (35) and Equation (36),

$$
\begin{aligned}
& (X-S)\left[\left(\mathrm{d}^{3} G / \mathrm{d} x^{3}\right) a+\mathrm{d} G / \mathrm{d} t+1 / 2\left(\mathrm{~d}^{4} x / \mathrm{d} x^{4}\right) b b d t+d^{3} G / d x^{3} b d z+\left(m_{2}-1\right) / 3 m_{1}\right] \\
& =\sum e \mu^{-1}+\sigma^{2} \phi\left(\mu+\sigma^{2}-\ln k_{1}\right)+36 x \sigma^{2} \\
& =e^{i} i \theta x+i \theta x I|x<1| \Pi+s^{\prime \prime}\{(x-\mu)(x-\mu)(x-\mu) / \sigma\}
\end{aligned}
$$

\section{Case 3: The Risk-Taker}


Put Purchase Euro Transactions for the Risk-Taker.

Risk-Takers have identical functions to moderate risk-takers in Figure 5 and Figure 6, along with Equation (31), Equation (32), Equation (33), Equation (34), and Equation (35). The only additional element is that the risk-taker is willing to trade put options until the minimum Euro level is reached before the central bank increases interest rates, restoring the Euro to its targeted rate. Moderate risk-takers are more cautious, trading puts for a few rounds, fearing central bank intervention, if they pursue additional profits by tarrying until Euro levels reach a minimum. Therefore, Figure 7 depicts a lower boundary $M N$, described by the upper limit of the threshold of the inflation rate, the long-term interest rate, and government debt $\left(k_{1}, k_{2}, k_{3}\right)$ in the intersection of the utility function with the Levy-Khintchine process. For the necessary condition for maximum utility, we equate Equation (34) to the Levy-Khintchine process to obtain the necessary condition to achieve maximum utility,

$$
\begin{aligned}
& (X-S) *\left[\left(\frac{d G}{d x}\right) a+\frac{d G}{d t}+1 / 2 \frac{d^{2} x}{d x^{2} b^{2} d t}+\frac{d G}{d x b d z}+\frac{m_{2}-1}{3 m_{1}}\right] \\
& =\left[e^{\mu}+\sigma^{2} \phi\left(\mu+\sigma^{2}-\ln k_{1}\right) x / \sigma\right]+\left[e^{\mu}+\sigma^{2} \phi\left(\mu+\sigma^{2}-\ln k_{2}\right) x / \sigma\right] \\
& \quad+\left[e^{\mu}+\sigma^{2} \phi\left(\mu+\sigma^{2}-\ln k_{3}\right) x / \sigma\right]+\left(e^{\sigma 2}+2\right) \sqrt{\left(e^{\sigma 2}-1\right)} \\
& \quad+\left(x^{4} \sigma^{2}+2 x^{3} \sigma^{2}+3 x^{2} \sigma^{2}-6\right)+(3 \mu+4.35 \sigma x)
\end{aligned}
$$

The sufficient condition for maximum put gain is the second derivative of Equation (38),

$$
\begin{aligned}
& (X-S)\left[\left(\frac{d^{2} G}{d x^{2}}\right) a+\frac{d G}{d t}+\frac{d^{2} G}{d x^{2} b d z}+\frac{m_{2}-1}{3 m_{1}}\right] \\
& =e^{\mu}+\sigma^{2} \phi\left(\mu+\sigma^{2}-\ln k\right)+\frac{1}{2 e \sigma}+16 \sigma^{2}+3.35 \sigma
\end{aligned}
$$

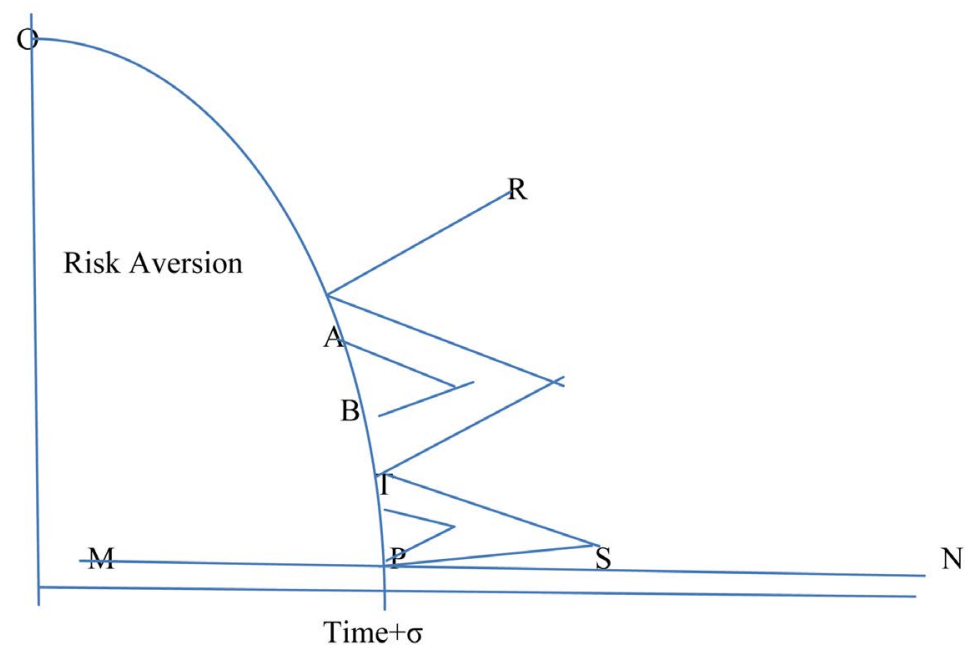

Figure 7. A range of maxima are obtained by equating Equation (34) to the Levy-Khintchine put option price distribution at $A, B, T$, and $P$. Source: Section 3.2, This Paper. 


\subsection{Pricing Put Options on the Australian Dollar and the New Zealand Dollar}

The Australian dollar and the New Zealand dollar are popular reserve currencies in Asia resulting in heavy daily trading, have minimal central bank intervention, are high interest rate currencies, and are countercyclical in movement in that these economies export commodities. Commodity prices fall with recessions depressing currency values. This is counter-cyclical to most currencies, whose central banks intervene to restore currency values during recessions [41]. At the World Economic Forum in Davos, Switzerland, the Central Bank of Russia announced the initiation of Australian dollar reserves [42]. The New Zealand dollar is one of the 10 most heavily traded of the world currencies [42]. The liquidity and lack of central bank action suggest that market forces adjust interest rates to restore currency value. Currency values are restored as the countries maintain a goal of macroeconomic stability. Short selling may continue for several rounds, as market forces are less swift or powerful as central banks in raising interest rates to end short selling. Put buying, on the other hand, may be more limited, as the volume of puts traded is less than that of other Western industrialized economies, the derivatives markets being dominated by futures, rather than options.

\section{Case 1: The Risk-Averse Investor}

The risk-averse investor will short sell the Australian dollar and the New Zealand dollar for a few rounds longer than the other currencies, knowing that market forces will not restore currency values and end short sale profits in a timely fashion. However, the lack of liquidity in the options markets indicates that the investor may forego trading in put options, with the few options available being highly risky, and therefore incompatible with the risk-averse inclinations of the investor. We assume that the optimal short sale price will lie at the intersection of the investor's hyperbolic cosine distributed utility function and the Weiner process of put option prices. Volatility may be limited, given the goal of stability. Therefore, two gradient vectors may capture the skewness risk of increased future currency risk, and the kurtosis risk of outliers. A Weiner process is assumed because of the characteristic of having independent increments. For every time interval in the future, and $t$, the future increments, $W_{t+u}-W_{t u}=0, u$ $\gtrsim 0$, are independent of past figures. The Australian dollar and New Zealand dollar's reliance on market forces to restore currency values in multiple steps, the Weiner process (see Figure 8), may approximate short sale prices most closely.

At point $T$, the point of intersection of the investor's utility function, $R S$, with the Weiner process of short sale prices, $O P$, both the hyperbolic cosine distribution and the Weiner process are expressed as a Taylor series expansion with

$$
G=\left[€_{o t}+\sqrt{2} \sum(\sin \Pi n t)(\Pi n)\right] \text { for the Weiner process, }
$$

$€_{0}=$ independent Gaussian variable with mean 0 and standard deviation of 1 , 


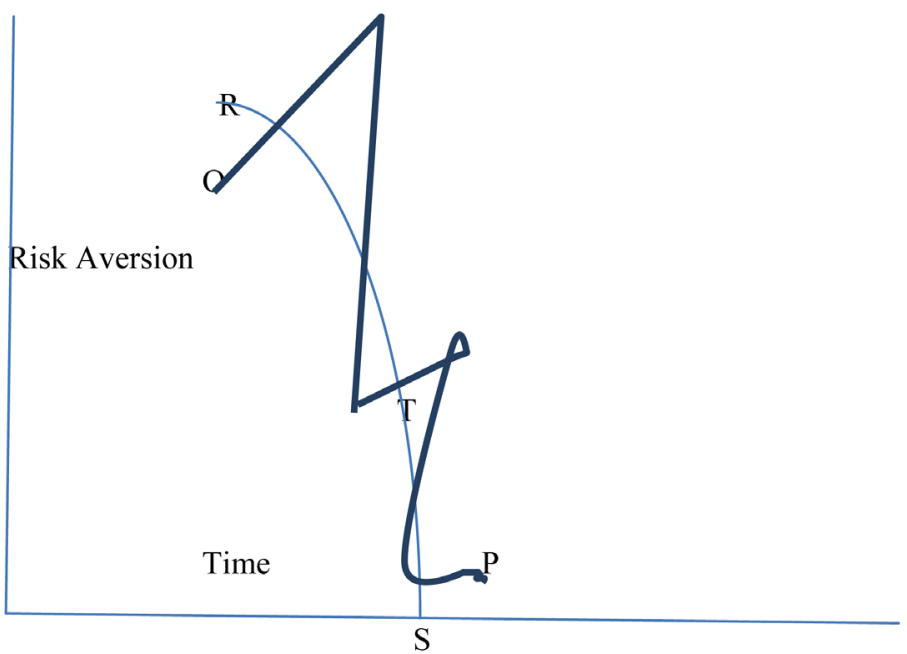

Figure 8. Short-sale transactions of the risk-averse investor in Australian Dollars and New Zealand Dollars. Maximum short sale gain is achieved at $T$, the point of intersection of the investor's hyperbolic cosine utility function and the Weiner process of short sale prices. At $T$ Australian dollars or New Zealand dollars are shorted at the highest price, followed by repurchase on price depreciation. Source: Section 3.3, This Paper.

$\nabla g=$ gradient vector for skewness, $\nabla h=$ gradient vector for kurtosis, Equating the utility function with a Taylor series with the Weiner process,

$$
\begin{aligned}
\sum\left(x^{2 n} / 2 n !\right)= & d G / d x \cdot d x+d G / d t+1 / 2 d^{2} G / d x^{2} \cdot d x^{2} \\
& +d^{2} G / d x \cdot d t+1 / 2 d^{2} G / d t^{2}+\nabla g^{2}+\nabla h^{2}
\end{aligned}
$$

Upon differentiating both sides, the moments $>2$ may be omitted, as the gradient vectors capture the volatility in the higher moments,

$$
2 n / 2 n !=d^{2} G / d x^{2} \cdot d x+d G / d t+\nabla g^{2}+\nabla h^{2}
$$

Equation (42) is the necessary condition for maximum short sale gain $(S-P)$ or (Selling Price - Purchase Price).

$$
\begin{aligned}
(S-P)(2 n / 2 n !) x= & d^{2}\left[\sum €_{0 t}+\sqrt{\sin \Pi n t} / \Pi n\right] / d x^{2} \\
& +d\left[\sum \sin \Pi n t / \Pi n\right] / d t+\nabla g^{2}+\nabla h^{2}
\end{aligned}
$$

The sufficient condition for maximizing short sale gains is,

$$
(S-P)(2 n / 2 n !)=d(\sin \Pi n t / \Pi n) / d t+\nabla g g+\nabla h h
$$

The risk-averse investor foregoes put buying as the limited trading of options in these markets imposes excessive volatility about future put prices.

\section{Case 2: The Moderate Risk-Taker}

The moderate risk-taker will expect a payoff for taking the risky short sale for a few more rounds to compensate for the additional risk of uncertain timing of the increase in interest rates.

Adding the penalty for additional risk which is Pratt's [37], compensation for accepting risk to the utility function of the investor and equating to the Weiner process in Equation (41), 


$$
\begin{aligned}
& \sum[2 n / 2 n !] x+\left(1 / 2 h^{r x}+0 h^{2 x}\right) \\
& =d G / d x \cdot d x+d G / d t+1 / 2 d^{2} G / d x^{2} \cdot d x^{2}+d^{2} G / d x d t \\
& +1 / 2 d^{2} G / d t^{2}+\nabla g g+\nabla h h
\end{aligned}
$$

Eliminating moments $>3$ upon differentiating,

$$
\begin{aligned}
& {[2 n / 2 n !] x+\left(1 / 2 h^{r}+0 h^{r 2}\right)} \\
& =d^{2} \sin \Pi n t / \Pi n / d x \cdot d x+d^{2} \sin \Pi n t / \Pi n / d t+\nabla g^{2}+\nabla h^{2} \\
& {[2 n / 2 n !]+\left(1 / 2 h^{r}+0 h^{2}\right)=-\sin \Pi n t / \Pi n-\sin \Pi n t / \Pi n}
\end{aligned}
$$

The function for maximum gain on short selling is,

$$
(S-P)[2 n / 2 n !] x+\left(1 / 2 h^{r}+0 h^{r 2}\right)=-\sin \Pi n t / \Pi n-\sin \Pi n t / \Pi n
$$

The moderate risk-taker expects that the minimum Australian dollar or New Zealand dollar price,

$$
E(M x)=\int\left(m \sqrt{2} / \Pi x \cdot e-m_{2} / 2 x\right) d m
$$

where, $E\left(M_{x}\right)=$ expected minimum exchange rate, $m=$ actual minimum exchange rate, At the boundary, we add Equation (46) to the Taylor series in Equation (44), to obtain the necessary condition for maximum short sale gain,

$$
\begin{aligned}
\sum x^{2 n} / 2 n != & d G_{1} / d x \cdot d x+1 / 2 d^{2} G_{1} / d x^{2}+d^{2} G_{1} / d x \cdot d t+d G_{2} / d x \cdot d x \\
& 1 / 2 d^{2} G_{2} / d x^{2}+d^{2} G^{2} d x \cdot d t+1 / 2 d^{2} G_{1} / d x^{2}+d^{2} G_{1} / d x \cdot d t \\
& d G_{2} / d x \cdot d x+\nabla g^{2}+\nabla h^{2}
\end{aligned}
$$

Differentiating (50), while omitting moments higher than 2,

$$
\begin{aligned}
& (S-P) x^{2 n} / 2 n ! \\
= & d^{2} G_{1} / d x \cdot d x+d^{2} G_{1} / d t^{2}+d^{2} G_{2} / d x \cdot d t+d^{2} G^{2} / d t^{2}+\nabla g^{2}+\nabla h^{2} \\
\text { Setting } G_{1}=€_{0}+\sqrt{\sum \sin \Pi n t} / \Pi n & G_{2}=\int\left(m_{1} \sqrt{2} / \Pi x \cdot e-m_{2} / 2 x\right) d m \\
(S-P) x^{2 n} / 2 n ! & \\
= & d^{2}\left[€_{0}+\sqrt{\sum \sin \Pi n t} / \Pi n\right] / d x \cdot d x+d^{2}\left[€_{0}+\sqrt{\sum \sin \Pi n t} / \Pi n\right] / d t^{2} \\
+ & d^{2} \int\left(m_{1} \sqrt{2} / \Pi e-m_{2} / 2 x\right) d m / d x \cdot d x \\
+ & d^{2} \int\left(m_{1} \sqrt{2} / \Pi x \cdot e-m_{2} / 2 x\right) d m / d t^{2}+\nabla g^{2}+\nabla h^{2}
\end{aligned}
$$

Upon differentiating Equation (54), we obtain the sufficient condition for maximum short sale gain,

$$
\begin{aligned}
& (S-P) * 2 n x / 2 n ! \\
= & d^{2}[\sqrt{\sin \Pi n t} / \Pi n] / d x+d^{2}[\sqrt{\sin \Pi n t} / \Pi n] / d t^{2} \\
& d^{2}\left(m_{1} \sqrt{2} / \Pi x . e m_{2} / 2 x\right) / d x+d^{2}\left(m_{1} \sqrt{2} / \Pi x . e-m_{2} / 2 x\right) / d t^{2}+\nabla g^{2}+\nabla h^{2}
\end{aligned}
$$

For the put buy option, only one round of trading may be expected, given the 
lack of liquidity in the options market for these currencies.

The utility function is equated to the Levy-Khintchine distribution for put prices in Equation (56),

$$
(X-S)=\sum\left[x^{2 n} / 2 n !\right]+1 / 2\left(h^{r}+0 h^{2}\right)=e^{\wedge} i \theta x I|x<1|+\nabla g^{2}+\nabla h^{2}
$$

The necessary condition from the differentiation of (56) is,

$$
(X-S)=\sum\left[x^{2 n} / 2 n !\right]=e^{i} i \theta x-i \theta x I|x<1|
$$

The sufficient condition for maximum put gain is obtained by differentiating Equation (57) as follows,

$$
(X-S)=[2 n x / 2 n !]=e^{i} i \theta x-i \theta x I|x<1|
$$

\section{Case 3: The Risk-Taker.}

The risk-taker follows the same choices as the moderate risk-taker for short selling. However, for put buying, the investor relies on personal judgment of the situation, rather than past experience. A utility function that ignores past experience is a continuous time martingale of the form,

$$
\left.M_{t}=p(W t, t)-\int\left[\partial x / \partial t+1 / 2 \partial^{2} x / \partial x^{2}\right](W t, s) d s\right] p(x, t)
$$

Differentiating Equation (59) to obtain the necessary condition for maximum put gain,

$$
=p^{\prime}(W t, t)-\left(\partial x / \partial t+1 / 2 \partial^{2} x / \partial x^{2}\right) p^{\prime}(x, t)
$$

Setting $t=x$, and omitting moments $>2$, the sufficient condition for maximum put gain is,

$$
=p^{\prime \prime}(W t, t)-(\partial x / \partial x . \partial x / \partial x) p^{\prime}(x, t)
$$

Therefore, combining with the Levi-Khintchine formula, we solve for put gain $(X-S)$ for small and large jumps, respectively, as,

$$
\begin{gathered}
p^{\prime}(W t, t)-\left(\partial 2 x / \partial x^{2}\right) p^{\prime}(x, t) e(i \theta x)^{-1}-i \theta x I|x<1| \\
p^{\prime}(W t, t)-\left(\partial 2 x / \partial p^{\prime}(x, t) e(i \theta)^{-1}-i \theta x I|x<1|\right.
\end{gathered}
$$

\subsection{Pricing Put Options on the Mexican Peso}

Only the risk-taker is assumed to invest in the Mexican peso, due to its history of external debt default in 1982, and capital flight [42], the risk-taker assumes considerable risk in investing in the peso. Therefore, it is likely, since excessive volatility may make predictability of the decline in the peso uncertain, that the investor will embark upon put option trading rather than short selling as put buying involves a lesser penalty (only the premium) than short selling (loss on borrowing), that put purchasing will be the optimal choice. We assume a rapid decline in risk aversion, or willingness to assume risk, which is more closely approximated by a diagonal line (see Figure 9), than a curve, which intersects with a Laplace distribution of put prices. The Laplace distribution is a double exponential distribution, which accounts for the highly skewed and rapid descent of 


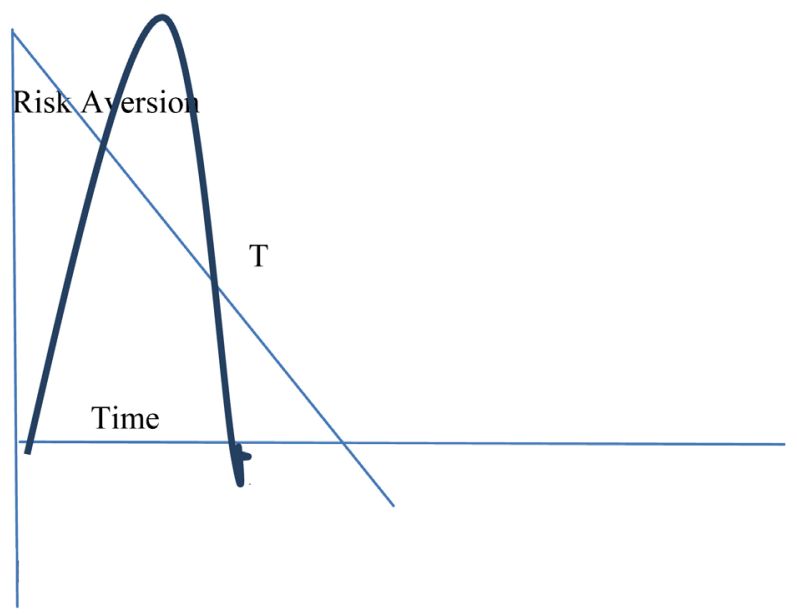

Figure 9. Put purchase transactions for the risk-taker on the Mexican Peso. Put buyers exercise at $T$, the intersection of the diagonal risk aversion function and the Laplace distribution price function to maximize gain upon repurchase of the Mexican peso at the lowest point of the diagonal line. Source: Section 3.4, This Paper.

put options on the peso. The point of intersection, $T$, represents the maximum gain for the put investor, and is represented as the first derivative of the following expression,

$$
(X-S) *\left(m_{1}+m_{2} / m_{1}\right) x=1 / 2 b[x \mu+x / b]+s *[L(x-\mu) / \sigma]
$$

The first derivative is,

$$
(X-S) *\left(m_{1}+m_{2} / m_{1}\right)=1 / 2 b[(\mu+x) / b] x+s * L^{\prime}(x-\mu) / \sigma
$$

The sufficient condition for maximum put gain is the first derivative of Equation (65),

$$
(X-S) *\left(m_{1}+m_{2} / m_{1}\right)=1 / 2 b[(\mu+x) / b]+s^{*} L^{\prime \prime}(x-\mu) / \sigma
$$

\section{Conclusions}

This paper has created models of put valuation for four currencies with different characteristics. It has updated the pre-2000 literature on the topic, upholding the position that currencies have unique characteristics, and therefore must be described by different models. We also introduce the concept of multimarket trading into put purchase strategies. Investors are likely to trade in both the foreign currency market and the options market. First, they attempt to optimize gain in the currency market through short selling. However, short selling is restricted, as it includes borrowing. The borrowed currency must be repaid, and the short seller lacks control over the interest rate to be paid. Hence, short sellers take additional profits on declining currency values in the options market. Thus, investments in put options are not restricted to the derivatives market. They are part of a comprehensive currency + derivatives investment strategy that earns gains from all venues of trading in depreciating currencies, which includes both the currency market and the derivatives market. 
The Black-Scholes model initiated research in the valuation of stock options. While it was extremely successful in achieving this purpose, the practice of using the same model to value currency options is questionable. Currencies are fundamentally different from securities. Put options on securities do not display jumps, while those on foreign currencies are described by jump processes. This paper models put prices in terms of the Levy-Khintchine formula, which makes allowance for both small and large jumps. Further, currencies are more heterogeneous than stocks. The U.S. dollar's reserve currency status, the Australian and New Zealand dollar's lack of government intervention, the Euro's strict band of fluctuation, and the Mexican peso's volatility are all significant differences that impact put currency option values, much more than they impact security prices.

This paper views short sales and put option purchase decisions as being governed by investor preferences. Investors are heterogeneous in their beliefs. Therefore, it is reasonable to assume that they differ in perceptions of risk, and that these perceptions must be modeled as intersecting with investment opportunities, be they in short selling or put buying. Floor traders will find these models useful, as they present clients with investment choices. Certain clients will gravitate to safer choices, while others will accept more risk, and pay accordingly. The notion that such perceptions towards risk, termed absolute risk aversion, may change, has also been included in our models. If the reward is sufficiently attractive, risk-averse investors may revise their original investment choices, opting for risky short selling and put buying. Have we supported Miller's [12] contention that short sellers are rational, selling overpriced securities? Certainly, in that both short sellers and put buyers eliminate future gains in trading in depreciating currencies, so that their actions may be considered to be rational.

Certain limitations of these models must be considered. The paper does not address most emerging market currencies or Organization of Petroleum Exporting (OPEC) currencies. Given the rapid growth of the former, and the recent fluctuations in oil prices, put strategies on these currencies must be examined in future research. Short selling has been presented as a means to correct currency mispricing. What are the limitations of this practice? Can short selling correct mispricing of emerging market currencies? Other theoretical formulations must be developed to address this issue. Finally, the hyperbolic cosine distribution was presented as the utility function of choice for investors in this paper. Future examinations must consider other forms, such as Esscher transformed Geometric Levy processes, Legendre functions, or Lebesque integrals.

\section{Conflicts of Interest}

The authors declare no conflicts of interest regarding the publication of this paper.

\section{References}

[1] Watt, M. (2014) Eurex Finalises FX Futures and Options Launch Date. FX Week, 4.

[2] Daal, E. and Madan, D.B. (2005) An Empirical Examination of the Variance-Gamma 
Model for Foreign Currency Options. The Journal of Business, 78, 2121-2152. https://doi.org/10.1086/497039

[3] Pitarbarg, V. (2005) A Multi-Currency Model with FX Volatility Skew. Working Paper.

[4] Schogl, E. (2002) A Multicurrency Extension of the Lognormal Interest Rate Market Model, Finance and Stochastics, 6, 173-196. https://doi.org/10.1007/s007800100054

[5] Mikkelson, P. (2001) Cross-Country LIBOR Market Model. Unpublished Doctoral Dissertation, University of Aarhus.

[6] Ahn, C., Cho, D. and Park, K. (2007) The Pricing of Foreign Currency Options under Jump Diffusion Processes. Journal of Futures Markets, 27, 668-695. https://doi.org/10.1002/fut.20261

[7] Garman, M. and Kohlhagen, S. (1983) Foreign Currency Options Values. Journal of International Money and Finance, 2, 231-237. https://doi.org/10.1016/S0261-5606(83)80001-1

[8] Grabbe, O. (1983) The Pricing of Call and Put Options on Foreign Exchange. Journal of International Money and Finance, 2, 239-253. https://doi.org/10.1016/S0261-5606(83)80002-3

[9] Shastri, K. and Tandon, K. (1986) Valuation of Foreign Currency Options: Some Empirical Tests. Journal of Financial and Quantitative Analysis, 21, 145-160. https://doi.org/10.2307/2330734

[10] Stulz, R. (1982) Options on the Minimum or Maximum of Two Risky Assets. Journal of Financial Economics, 10, 161-185. https://doi.org/10.1016/0304-405X(82)90011-3

[11] Black, F. (1976) The Pricing of Commodity Contracts. Journal of Financial Economics, 3, 167-179. https://doi.org/10.1016/0304-405X(76)90024-6

[12] Miller, E. (1977) Risk, Uncertainty, and Divergence of Opinion. The Journal of Finance, 32, 1151-1168. https://doi.org/10.1111/j.1540-6261.1977.tb03317.x

[13] Lee, C.M. and Swaminathan, B. (2000) Price Momentum and Trading Volume. Journal of Finance, 55, 2017-2069. https://doi.org/10.1111/0022-1082.00280

[14] Abraham, R. (2005) An Exploration of Earnings Whispers Forecasts as Predictors of Stock Returns. Journal of Economic Studies, 32, 524-539. https://doi.org/10.1108/01443580510631405

[15] Chang, E.C., Cheng, J.W. and Yu, Y. (2007) Short-Sale Constraints and Price Discovery: Evidence from the Hong Kong Market. Journal of Finance, 62, $2097-2121$. https://doi.org/10.1111/j.1540-6261.2007.01270.x

[16] Diether, K.B., Malloy, C.J. and Scherbina, A. (2002) Differences of Opinion and Cross Section of Stock Returns. Journal of Finance, 57, 2114-2141. https://doi.org/10.1111/0022-1082.00490

[17] Morris, S.E. and Shin, H.S. (1998) Unique Equilibrium in a Model of Self-Fulfilling Currency Attacks. The American Economic Review, 88, 587-597.

[18] Mettier, U., Thony, M. and Schmidt, H. (2009) Carry and Trend Strategies in FX Markets. Journal of Asset Management, 11, 321-331. https://doi.org/10.1057/jam.2010.18

[19] Brunnermeir, M., Nagel, S. and Pedersen, L.H. (2008) Carry Trades and Currency Crashes. NBER Macroeconomics Annual, 23, 313-348. https://doi.org/10.1086/593088

[20] Klitgaard, T. and Weir, L. (2004) Exchange Rate Changes and Net Positions of Spe- 
culators in the Futures Market. Federal Reserve Bank of New York Economic Policy Review, 10, 17-28.

[21] Chen, J., Hong, H. and Stein, J.C. (2001) Forecasting Crashes: Trading Volumes, Past Returns and the Conditional Skewness in Stock Prices. Journal of Financial Economics, 61, 345-381. https://doi.org/10.1016/S0304-405X(01)00066-6

[22] Humpage, O.F. (1999) U.S. Intervention: Assessing the Probability of Success. Journal of Money, Credit, and Banking, 31, 731-747. https://doi.org/10.2307/2601220

[23] Frankel, J.A. (1995) Still the Lingua Franca: The Exaggerated Death of the Dollar. Foreign Affairs, 74, 9-16. https://doi.org/10.2307/20047203

[24] Shih, V. and Steinberg, D.A. (2012) The Domestic Politics of the International Dollar Standard: A Statistical Analysis of Support for the Reserve Currency, 2000-2008. Canadian Journal of Political Science, 45, 855-880. https://doi.org/10.1017/S0008423912001059

[25] Ailinea, A.G., Milea, C. and Jordache, F. (2012) An Analysis Regarding the Fulfillment of the Nominal Convergence Criterion in the New Member States of the European Union in the Context of the Current Financial Crisis. Economy Transdisciplinary Cognition, 15, 14-21.

[26] Chutasripanich, N. and Yettman, J. (2015) Foreign Exchange Interventions. Bank for International Settlements (BIS) Working Papers, 34.

[27] Grilli, U.V., Grilli, V.U. and Alesina, A. (1988) Can Speculative Attacks on EMS Currencies Be Avoided? Giornale degli Economisti e Annali di Economia, 47, 537-543.

[28] Black, F. and Scholes, M. (1973) The Pricing of Options and Corporate Liabilities. Journal of Political Economy, 27, 637-654. https://doi.org/10.1086/260062

[29] Ekvall, N., Jennergren, L.P. and Naslund, B. (1997) Currency Option Pricing with Mean Reversion and Uncovered Interest Parity: A Revision of the Garman-Kolhagen Model. European Journal of Operational Research, 100, 41-59. https://doi.org/10.1016/S0377-2217(95)00366-5

[30] Yang, H.C. (1983) A Note on Currency Option Pricing Models. Journal of Business Finance \& Accounting, 12, 429-438. https://doi.org/10.1111/j.1468-5957.1985.tb00844.x

[31] Wong, H.Y. and Zhao, J. (2010) Currency Option Pricing: Mean Reversion and Multi-Scale Stochastic Volatility. The Journal of Futures Markets, 10, 938-956. https://doi.org/10.1002/fut.20452

[32] Andersen, T.G., Benzoni, L. and Lund, J. (2002) An Empirical Investigation of Continuous-Time Equity Return Models. The Journal of Finance, 57, 1239-1284. https://doi.org/10.1111/1540-6261.00460

[33] Chernov, M., Gallant, A.R., Ghysels, E. and Tauchen, G. (2003) Alternative Models for Stock Price Dynamics. Journal of Econometrics, 116, 225-257. https://doi.org/10.1016/S0304-4076(03)00108-8

[34] Eraker, B. (2004) Do Stock Prices and Volatility Jump? Reconciling Evidence from Spot and Option Prices. The Journal of Finance, 59, 1367-1403. https://doi.org/10.1111/j.1540-6261.2004.00666.x

[35] Xiao, W. Zhang, W.G., Zhang, X.L. and Wang, Y.L. (2010) Pricing Currency Options in a Fractional Brownian Motion with Jumps. Economic Modeling, 27, 935-942. https://doi.org/10.1016/j.econmod.2010.05.010

[36] Ma, C. (2006) Intertemporal Recursive Utility and an Equilibrium Asset Pricing Model in the Presence of Levy Jumps. Journal of Mathematical Economics, 42, 
131-160. https://doi.org/10.1016/j.jmateco.2005.08.003

[37] Pratt, J.W. (1964) Risk Aversion in the Small and in the Large. Econometrica, 32, 122-136. https://doi.org/10.2307/1913738

[38] Prakash, A.J., Chang, C.-H. and Hamid, S. (1996) Why a Decision Maker May Prefer a Seemingly Unfair Gamble. Decision Science, 27, 239-251. https://doi.org/10.1111/j.1540-5915.1996.tb01717.x

[39] Brennan, M.J. (1979) The Pricing of Contingent Claims in Discrete Time Models. Journal of Finance, 34, 53-68. https://doi.org/10.1111/j.1540-6261.1979.tb02070.x

[40] Camara, A. (2001) The Valuation of Options with Restrictions on Preferences and Distributions. The Journal of Futures Markets, 21, 1091-1117. https://doi.org/10.1002/fut.2201

[41] Yeates, C. (2010) Aussie Now Fifth Most Traded Currency. The Sydney Morning Herald.

http://www.smh.com.au/business/aussie-now-fifth-mosttraded-currency-2010090114-nma.html

[42] Triennial Central Bank Survey (2014) Triennial Central Bank Survey, April 2013. http://bis.org/publ/rpfx.pdf 